PAULUS, D; VALMORBIDA, R; PAULUS, E. 2016. Ácido indolbutírico na propagação vegetativa de alecrim. Horticultura Brasileira 34 : $520-528$. DOI - http://dx.doi.org/10.1590/S0102-053620160411

\title{
Ácido indolbutírico na propagação vegetativa de alecrim
}

\author{
Dalva Paulus ${ }^{1}$; Raquel Valmorbida ${ }^{1}$; Eloi Paulus ${ }^{2}$ \\ ${ }^{1}$ Universidade Tecnológica Federal do Paraná(UTFPR), Campus Dois Vizinhos-PR, Brasil; dalvaufsmdeutch@yahoo.com.br (autor \\ para correspondência); raquelvalmorbida@yahoo.com.br; ${ }^{2}$ Universidade Federal de Santa Maria (UFSM),Santa Maria-RS, Brasil; \\ epaulus2000@yahoo.com.br
}

\section{RESUMO}

O alecrim (Rosmarinus officinalis) é uma planta de porte subarbustivo, utilizada como condimento e medicinal. A crescente demanda da indústria de fármacos pelo óleo essencial de alecrim vem despertando interesse da pesquisa sobre a propagação dessa espécie. O objetivo do trabalho foi avaliar o efeito do ácido indolbutírico (AIB) na propagação vegetativa por estaquia de alecrim em duas épocas do ano. Os experimentos foram conduzidos em ambiente protegido, em duas épocas, no período de novembro de 2010 a janeiro de 2011 (verão) e de abril a junho de 2011 (outono). O delineamento experimental foi blocos ao acaso, com quatro repetições, 20 estacas por repetição e os tratamentos foram seis concentrações de AIB (mg/L): 0, 1000, 1500, 2000,2500 e 3000 . As estacas tiveram a base imersa nas respectivas soluções com e sem AIB e foram colocadas para enraizar em tubetes contendo substrato comercial Mecplant ${ }^{\circledR}$. As características avaliadas nas estacas foram altura aos $7 ; 14 ; 21 ; 28 ; 35$ e 42 DAP, porcentagem de enraizamento, mortalidade, comprimento da maior raiz, massas fresca e seca da parte aérea e raízes, aos 42 DAP. A época do ano não influenciou significativamente no enraizamento e no crescimento de mudas de alecrim. A concentração de $2500 \mathrm{mg} / \mathrm{L}$ de AIB resultou em maior percentagem de estacas enraizadas (98\%), massas fresca $(0,75 \mathrm{~g} /$ planta $)$ e seca da parte aérea $(0,30 \mathrm{~g} /$ planta $)$; comprimento de maior raiz $(15,74 \mathrm{~cm})$, massas fresca $(0,65 \mathrm{~g} /$ planta $)$ e seca das raízes $(0,15 \mathrm{~g} /$ planta $)$ em relação às estacas sem tratamento com AIB. A aplicação de AIB nas concentrações avaliadas resultou em efeitos positivos para o enraizamento de estacas de alecrim, favorecendo o crescimento em altura e acúmulo de massas frescas e secas da parte aérea e das raízes, tornando assim, o enraizamento mais eficiente, possibilitando ao produtor de plantas medicinais a obtenção de mudas mais desenvolvidas em menor tempo.

Palavras-chave: Rosmarinus officinalis, estaquia, auxina, regulador de crescimento.

\begin{abstract}
Indolbutyric acid on rosemary vegetative propagation

Rosemary (Rosmarinus officinalis) is a subshrub sized plant, used as a condiment and for medicinal purposes. The growing demand for drugs derived from rosemary essential oil is attracting interest from research on the propagation of this species. The objective was to evaluate the effect of IBA on vegetative propagation of rosemary cuttings in two seasons. The experiments were carried out in greenhouse during two periods, from November 2010 to January 2011 (summer) and from April to June 2011 (autumn). The experimental design was randomized blocks with four replications and 20 cuttings per replication and treatments were six indole butyric acid concentrations (IBA) (mg/L): 0, 1000, 1500, 2000, 2500 and 3000 . The cuttings base was dipped in the respective solutions with and without AIB and were planted in tubes containing commercial substrate Mecplant ${ }^{\mathbb{R}}$. The characteristics evaluated in the stem cuttings were height at $7,14,21,28,35$ and 42 days after planting date, rooting percentage, mortality, the longest root length, fresh and dry weight of the aboveground part and roots. The season did not influence significantly rooting and growth of rosemary seedlings. The concentration of $2500 \mathrm{mg} / \mathrm{L}$ resulted in higher percentage of rooted cuttings $(98 \%)$, fresh $(0.75 \mathrm{~g} /$ plant $)$ and dry aboveground part mass $(0.30 \mathrm{~g} /$ plant $)$; length of the longest root $(15.74 \mathrm{~cm})$, fresh $(0.65 \mathrm{~g} / \mathrm{plant})$ and dry root mass $(0.15 \mathrm{~g} / \mathrm{plant})$ over the cuttings without treatment with IBA. The application of IBA on the evaluated concentrations resulted in positive effects for rooting of rosemary cuttings, favoring the growth in height and accumulation of fresh and dry weight of the aboveground part and roots, thus making more efficient rooting, enabling the medicinal plants producer to obtain more developed seedlings in less time.
\end{abstract}

Keywords: Rosmarinus officinalis, cutting, auxin, growth regulator.

(Recebido para publicação em 23 de julho de 2015; aceito em 15 de fevereiro de 2016) (Received on July 23, 2015; accepted on February 15, 2016)

A espécie Rosmarinus officinalis (Lamiaceae) conhecida popularmente como alecrim, é originária da Região Mediterrânea da Europa e cultivada em quase todos os países de clima temperado, de Portugal à Austrália (Lorenzi \& Matos, 2008). De acordo com os autores, a planta possui porte subarbustivo lenhoso, ereto e pouco ramificado de até $1,5 \mathrm{~m}$ de altura. As folhas são lineares, coriáceas e muito aromáticas, medindo 1,5 a $4 \mathrm{~cm}$ de comprimento por 1 a $3 \mathrm{~mm}$ de espessura. As flores são azulado-claras, pequenas e de aroma forte e muito agradável.

O alecrim é utilizado como planta aromática, medicinal e na culinária (Martins, 1998). De acordo com Sartoratto et al. (2004), o alecrim possui propriedades estimulantes, antiespasmódicas, antissépticas, antifúngicas e antibacterianas.

O óleo essencial também é utilizado na indústria de alimentos, na produção 
de balas, doces e bebidas, é composto pelos constituintes químicos alfa-pineno, cânfora, eucaliptol, borneol, canfeno, flavonoides, ácidos polifenólicos e ácido rosmarínico. Além desses, ainda estão presentes, em menor concentração, substâncias como taninos, ácidos e alcoóis (Cunha et al., 2003). No Brasil, devido ao aumento da demanda do óleo essencial pela indústria farmacêutica e a comercialização de alimentos com aditivos naturais, houve um maior interesse no cultivo dessa espécie.

Quando se objetiva a multiplicação de genótipos selecionados, a propagação por sementes promove grande variação, o que torna relevante o desenvolvimento de metodologias para propagação vegetativa (Oliveira et al., 2011). A propagação do alecrim, planta alógama, pode ser realizada por sementes ou estacas, porém quando por sementes, a planta demora de dois a três anos até atingir a fase adulta, podendo também aumentar a variabilidade genética, como no caso de cruzamentos de indivíduos contrastantes (Von Hertwig, 1991). A estaquia é um dos principais métodos de propagação vegetativa do alecrim pela vantagem dos descendentes serem iguais à planta-mãe, ser de baixo custo e de fácil obtenção.

A utilização de reguladores de crescimento vegetais tem por finalidade induzir o processo de formação de raízes, aumentar a percentagem de estacas enraizadas, o número e a qualidade das raízes formadas e a uniformidade do enraizamento (Miranda et al., 2004). As auxinas são os reguladores vegetais indicados para indução de enraizamento, sendo o ácido indolbutírico (AIB) um dos mais utilizados e mais eficientes, por ser foto estável e ser imune à ação biológica (Figueiredo et al., 2009).

As espécies pertencentes à família Lamiaceae diferem muito quanto à resposta de enraizamento a reguladores de crescimento. Scalon et al. (2003) informam que o comprimento da maior raiz $(11,5 \mathrm{~cm})$ de alecrim foi observado com AIB $250 \mathrm{mg} / \mathrm{L}+100 \mathrm{mg} / \mathrm{L}$ de boro. Pimenta et al. (2007), em trabalhos com estaquia de Lippia alba com diferentes auxinas verificaram que o AIB foi a auxina mais eficiente na indução de rizogênese em estacas.

Estudos sobre a propagação de espécies medicinais são de elevada importância, uma vez que servem de base para o sucesso do cultivo dessas plantas a nível comercial (Carvalho Júnior et al., 2009). Pesquisas sobre a propagação vegetativa do alecrim utilizando reguladores de crescimento ainda são incipientes. $\mathrm{O}$ presente trabalho foi realizado com o objetivo de avaliar o efeito do AIB na propagação vegetativa por estaquia de alecrim em duas épocas do ano.

\section{MATERIAL E MÉTODOS}

Os experimentos foram conduzidos na área experimental da Universidade Tecnológica Federal do Paraná (UTFPR), Campus Dois Vizinhos, em casa de vegetação tipo arco, com cobertura plástica de polietileno de baixa densidade de $150 \mu \mathrm{m}$, realizados em duas épocas, sendo o primeiro conduzido no verão no período de novembro de 2010 a janeiro de 2011; e o segundo no outono no período de abril a junho de 2011.

As estacas apicais com $8,0 \mathrm{~cm}$ de comprimento foram obtidas de quatro plantas matrizes, cultivadas há quatro anos, localizadas no horto medicinal da UTFPR. Retirou-se o mesmo número de estacas (120) por planta por tratamento.

As estacas foram cortadas em bisel e retiradas as folhas da base. Estas tiveram a base imersa $(1,0 \mathrm{~cm})$, durante dez segundos (Coelho \& Messias, 2000) em solução hidroalcoólica de AIB $(5 \mathrm{~mL}$ por tratamento) com as concentrações $(\mathrm{mg} / \mathrm{L})$ de: 0, 1000, 1500, 2000, 2500 e 3000 (Coelho \& Messias, 2000), que foram obtidas por meio da dissolução de ácido indol-3-butírico $\left(\mathrm{C}_{12} \mathrm{H}_{13} \mathrm{NO}_{2}\right)$ p.a., com $99 \%$ de pureza, produzido pela MERCK ${ }^{\circledR}$ em solvente composto de $50 \%$ de água destilada e $50 \%$ de álcool etílico p.a. de $99,5 \%$ de pureza (Hartmann et al., 2011).

Após os tratamentos, as estacas foram enterradas a $1,0 \mathrm{~cm}$ e colocadas em ângulo de $90^{\circ}$ para enraizar em tubetes com dimensões de diâmetro de bocal de $38 \mathrm{~mm}, 8$ estrias, altura de $120 \mathrm{~mm}$ e volume de $80 \mathrm{~cm}^{3}$, contendo substrato comercial Mecplant $^{\circledR}$. Os tubetes foram organizados em grade de arame suporte, de forma suspensa, mantidos em casa de vegetação tipo arco, com cobertura plás- tica de polietileno de baixa densidade de $150 \mu \mathrm{m}$. As irrigações foram realizadas com microaspersores, três vezes ao dia, durante 30 minutos, totalizando $6,6 \mathrm{~mm} / \mathrm{dia}$.

O delineamento experimental utilizado foi blocos ao acaso, com quatro repetições e seis concentrações de ácido indol butírico (AIB). Foram utilizadas 20 estacas por repetição, totalizando 480 estacas.

As observações de altura da muda foram obtidas por meio de medidas realizadas com régua da base até o ápice da planta aos 7, 14, 21, 28, 35 e 42 dias após o plantio. As determinações do comprimento da maior raiz, percentagem de estacas enraizadas, a massa fresca da parte aérea e das raízes foram realizadas aos 42 DAP. As raízes e parte aérea foram colocadas em estufa com circulação de ar forçada a $65^{\circ} \mathrm{C}$ até massa constante.

Os resultados foram processados no programa "SAS Studio" (SAS Institute, 2014). Os dados foram submetidos à análise de variância com teste $\mathrm{F}$ $(\mathrm{p}<0,01)$ e aplicada análise de regressão polinomial.

\section{RESULTADOS E DISCUSSÃO}

\section{Experimento de verão}

O comportamento da variável altura das mudas de alecrim foi influenciado pelas diferentes concentrações de AIB. A concentração de $2500 \mathrm{mg} / \mathrm{L}$ de AIB resultou em maior altura em relação às demais concentrações de AIB testadas em todos os períodos de avaliação (Figura 1). As estacas enraizadas na concentração zero de AIB apresentaram os menores valores de altura.

Verificou-se que, conforme o aumento das concentrações de AIB (0, 1000, $1500,2000,2500 \mathrm{mg} / \mathrm{L}$ ) aplicadas nas mudas, ocorreu acréscimo em altura. Porém, com a dose de $3000 \mathrm{mg} / \mathrm{L}$ ocorreu decréscimo em altura. Este comportamento pode estar relacionado com o fato de elevadas concentrações de auxina poderem ser tóxicas à planta afetando a formação de raízes e o crescimento da parte aérea (Pasqual et al., 2001).

Paradikovic et al. (2013) observaram 


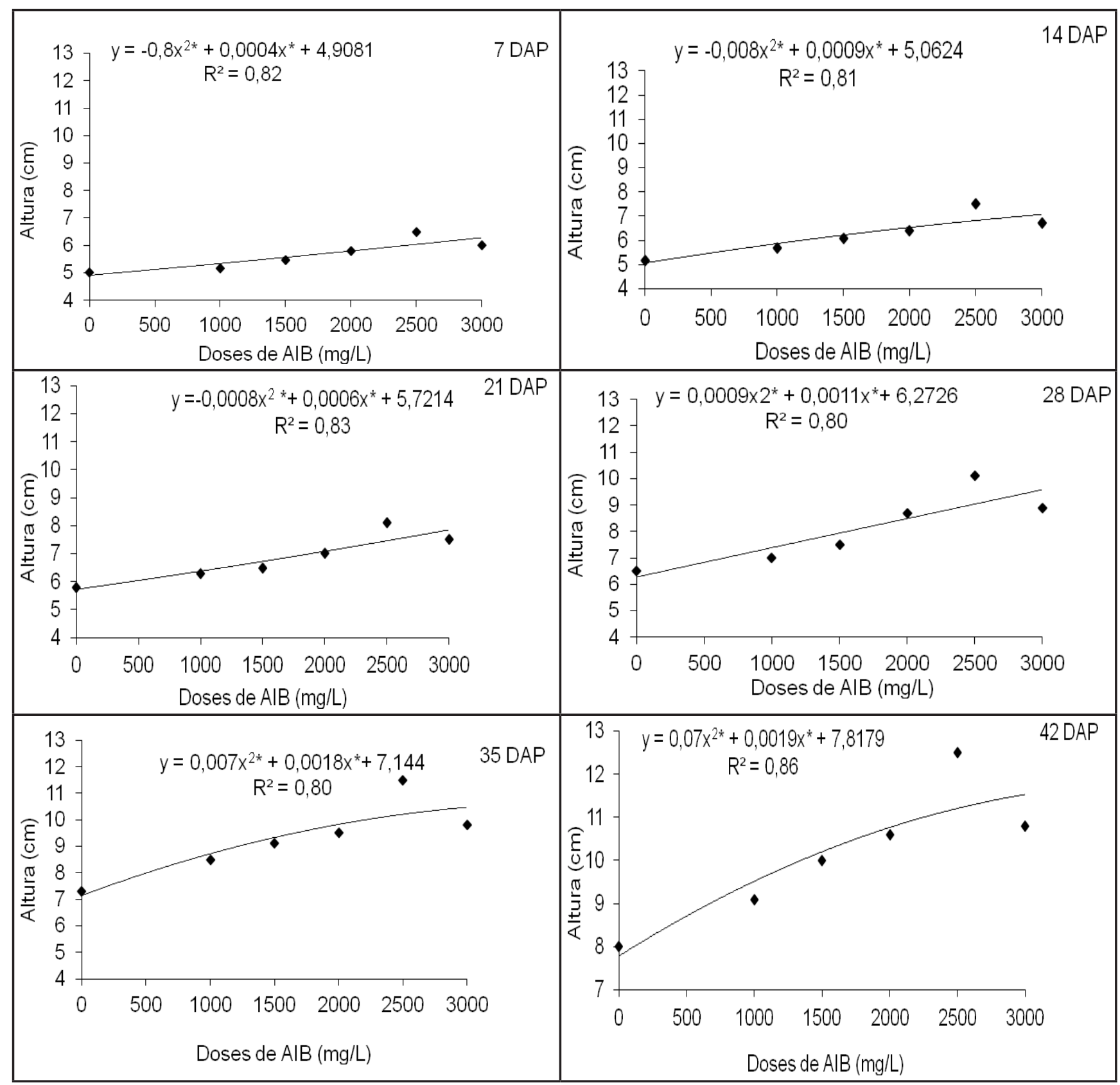

Figura 1. Alturas de estacas de alecrim (Rosmarinus officinalis) em resposta à aplicação de doses de ácido indol butírico (AIB) avaliadas aos 7, 14, 21, 28, 35 e 42 DAP (dias após o plantio), no verão. *significativo a p $<0,01$ \{height of rosemary cuttings (Rosmarinus officinalis) in response to application of indole-butyric acid doses (IBA), evaluated at 7, 14, 21, 28, 35 and 42 DAP (days after planting), in the summer. *significant $\mathrm{p}<0.01\}$. Dois Vizinhos, UTFPR, 2010.

o efeito positivo do AIB em produto comercial Rhizopon $\mathrm{I}^{\circledR}(0,5 \%$ de AIB) no crescimento em altura de estacas de alecrim em relação às estacas sem tratamento de AIB.

Os autores discordam do trabalho de Coelho \& Messias (2000) com o objetivo de avaliar o efeito de várias concentraçoes de ácido indolbutírico no enraizamento de estacas de alecrim, que constataram que as concentraçoes de 1000 a 2000 mg/L de AIB proporciona- ram maior número de folhas nas estacas, mas não alteraram o comprimento da maior raiz e altura da estaca.

A altura é um dos parâmetros mais utilizados na classificação e seleção de mudas nos viveiros, sendo considerada como uma das mais importantes características para se estimar o potencial de desempenho das plantas no campo (Carneiro, 1995).

A quantidade de estacas enraizadas foi influenciada pelas doses de AIB,
(Figura 2a). A dose de $2500 \mathrm{mg} / \mathrm{L}$ de AIB resultou em maior enraizamento (98\%), enquanto que sem o uso de AIB apresentou o menor valor (53\%) de enraizamento quando comparada aos demais tratamentos. A alta percentagem de estacas enraizadas com o uso de AIB, pode estar relacionada ao fato de que a auxina pode ter estimulado a síntese de etileno, favorecendo a emissão de raízes, e o enraizamento de estacas (Ramos et al., 2003). 


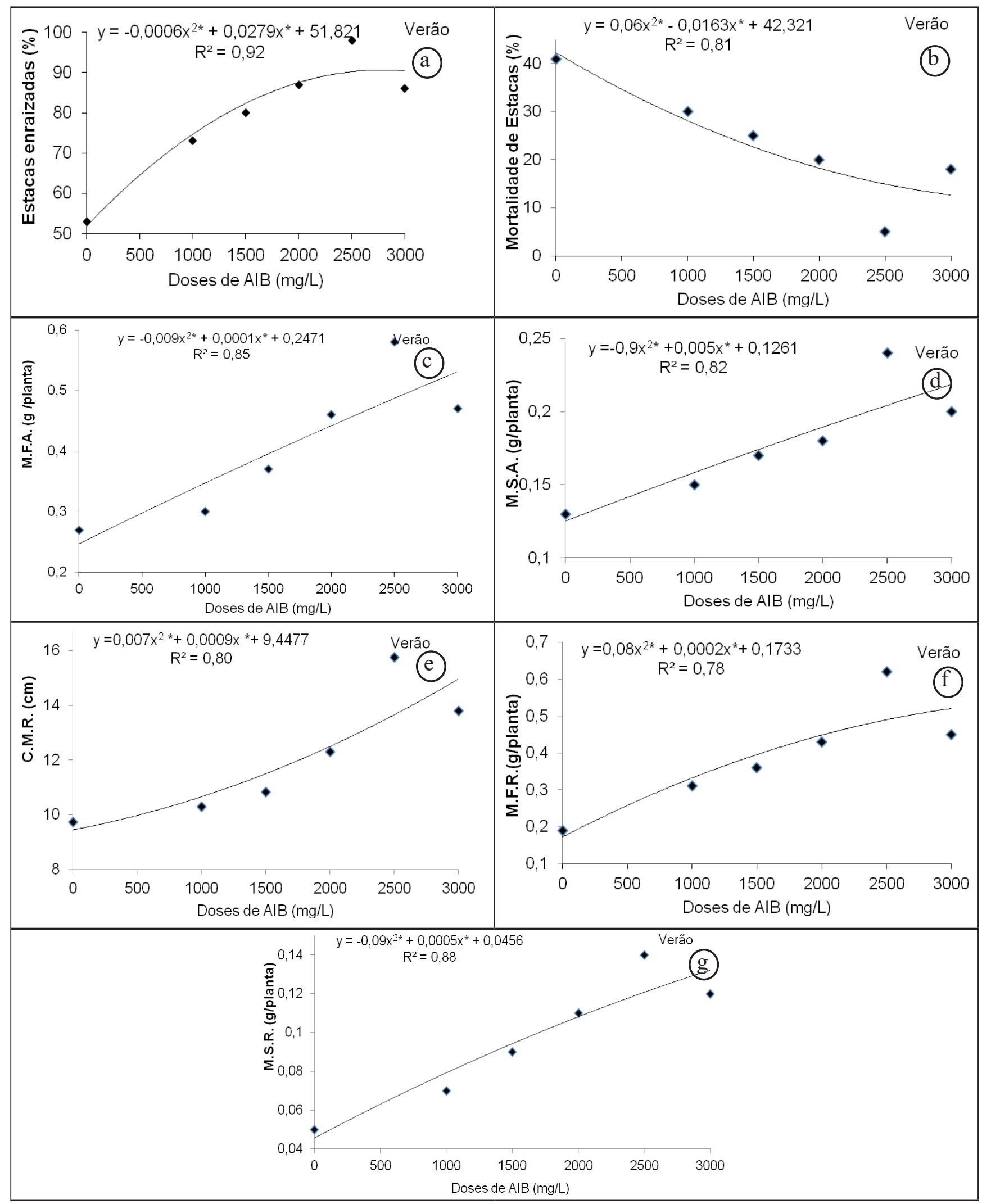

Figura 2. Estacas enraizadas (a); mortalidade de estacas (b); massa fresca da parte aérea (M.F.A.) (c); massa seca da parte aérea (M.S.A.) (d); comprimento de maior raiz (C.M.R.) (e); massa fresca das raízes (M.F.A.) (f) e massa seca das raízes (M.S.R) (g) de estacas de alecrim em função de concentrações de AIB, avaliadas aos 42 DAP (dias após o plantio) no verão.*significativo a p $<0,01$. \{rooted cuttings (a); mortality of cuttings (b); aboveground part fresh mass (M.F.A.) (c); aboveground part dry matter (M.S.A.) (d); length of the longest root (C.M.R.) (e); fresh matter of roots (M.F.A.) (f) and dry matter of roots (M.S.R) (g) of rosemary stems in response to different concentrations of IBA), 42 DAP (days after planting) in summer. *significant $\mathrm{p}<0.01\}$. Dois Vizinhos, UTFPR, 2010. 
Também, as condições climáticas de temperaturas amenas, com médias de 21,$04 ; 22,22 ; 23,60$ e $23,29^{\circ} \mathrm{C}$ nos meses de novembro, dezembro de 2010; janeiro e fevereiro de 2011, respectivamente, são favoráveis ao enraizamento de estacas da maioria das espécies da família Lamiaceae (Von Hertwig, 1991). De acordo com o autor, é recomendável que a propagação do alecrim seja realizada na primavera ou verão, sendo considerada como ótima a temperatura até $25^{\circ} \mathrm{C}$ para o enraizamento de estacas e crescimento da maioria das plantas aromáticas e medicinais herbáceas. Deen \& Mahmoud (1996) observaram que estacas de alecrim coletadas na primavera apresentaram melhor enraizamento em relação ao verão, outono e inverno. Segundo Hartmann et al. (2011), na primavera-verão são iniciados os períodos de crescimento mais ativos nas plantas. Além disso, o material de reserva está disponível, possibilitando o desenvolvimento das raízes.

O efeito positivo do AIB no enraizamento de estacas, também foi constatado por Paradikovic et al. (2013) que obtiveram $93 \%$ de estacas de alecrim enraizadas com aplicação de produto comercial Rhizopon $\mathrm{I}^{\circledR}(0,5 \%$ de AIB). Oliveira et al. ( 2011) avaliaram altas concentrações de AIB (2000 e 4000 mg/L) na sobrevivência e enraizamento de estacas de Hyptis leucocephala e Hyptis platanifolia, espécies da mesma família do alecrim, Lamiaceae, e constaram maior percentagem de enraizamento naquelas tratadas com 2000 mg/L de AIB. Segundo Ramos et al. (2003), as auxinas são essenciais no processo de enraizamento, possivelmente por estimularem a síntese de etileno, favorecendo a emissão de raízes. De acordo com Pasqual et al. (2001), elevadas concentrações de auxina podem ser tóxicas à planta, causando formação de calos na base das estacas, afetando a formação de raízes e o crescimento da parte aérea. Para o alecrim não foram verificados efeitos fitotóxicos na base das estacas com as doses de AIB avaliadas. No entanto, observou-se um decréscimo no enraizamento de estacas com a dose de $3000 \mathrm{mg} / \mathrm{L}$.

Bona et al. (2012), avaliando 8 acessos de lavanda (Lavandula angustifolia) em quatro concentrações $(0,700,1500$ e $2000 \mathrm{mg} / \mathrm{L})$ de AIB observaram que os acessos apresentaram diferentes respostas à aplicação de AIB. A dose de $1500 \mathrm{mg} / \mathrm{L}$ de AIB promoveu melhor enraizamento, maior número e comprimento de raízes no genótipo G6, mas foi prejudicial para o genótipo G8. Segundo os autores, a recomendação de uso e doses de auxina para induzir o enraizamento de uma espécie não pode ser generalizada e deve ser ajustado para diferentes genótipos de lavanda. No presente trabalho, a concentração de $2500 \mathrm{mg} / \mathrm{L}$ de AIB foi a que promoveu o melhor enraizamento de estacas de alecrim.

Em relação à mortalidade de estacas ocorreu efeito significativo em função das concentrações de AIB (Figura 2b). A menor taxa de mortalidade entre estacas (5\%) foi na concentração de $2500 \mathrm{mg} / \mathrm{L}$ (Figura 2b). Verificou-se alta taxa de mortalidade $(41 \%)$ de estacas sem uso de AIB, justificando a utilização de regulador de crescimento para enraizamento de estacas de alecrim.

Analisando os resultados de massas fresca e seca da parte aérea, comprimento da maior raiz e massas fresca e seca das raízes verificaram-se diferenças significativas entre as concentrações de AIB avaliadas (Figuras 1c; 1d; 1e; 1f). A concentração de $2500 \mathrm{mg} / \mathrm{L}$ de AIB resultou em maiores massas fresca e seca da parte aérea $(0,58$ e $0,24 \mathrm{~g} / \mathrm{plan}$ ta), respectivamente; maiores massas fresca $(0,62 \mathrm{~g} /$ planta $)$ e seca das raízes $(0,14 \mathrm{~g} /$ planta $)$ e comprimento da maior raiz $(15,74 \mathrm{~cm})$. Verificou-se que as estacas enraizadas na concentração zero de AIB resultaram nos menores valores de massas frescas e secas da parte aérea e das raízes.

Segundo Bona et al. (2010), a massa seca de raízes de lavanda (Lavandula dentata, Lamiaceae) aumentou proporcionalmente com as concentrações de AIB (0; 500; 1000; 2000; $3000 \mathrm{mg} / \mathrm{L})$. Segundo os autores, as raízes tratadas com as doses mais elevadas de AIB apresentaram qualidade superior, sendo mais densas e bem formadas, característica desejável no momento do plantio da muda a campo.

Observou-se que o AIB melhorou a qualidade das raízes, sendo estas ramifi- cadas, aderidas ao substrato e formadas de diversos nós da estaca, e não apenas a partir da base da estaca. Paradikovic et al. (2013), utilizando produto comercial Rhizopon $\mathrm{I}^{\circledR}(0,5 \%$ de AIB) constataram efeito significativo do AIB sobre a massa fresca de estacas de alecrim em relação às estacas sem tratamento. A aplicação de auxinas exógenas nas estacas de alecrim propiciou efeitos favoráveis ao crescimento, qualidade do sistema radicular e enraizamento de estacas. Pasqual et al. (2001) informam que a aplicação de auxinas, como o AIB, na maioria das espécies de plantas, propicia efeitos benéficos à massa e à qualidade do sistema radicular de estacas, fato esse observado nas épocas de verão e inverno do presente estudo.

Segundo Kramer \& Kozlowski (1972), a utilização de dosagens adequadas do regulador de crescimento é muito importante, pois as concentrações ótimas variam com as espécies estudadas, bem como, aos diversos tipos de indutores sintéticos existentes. Ainda segundo os autores, após o tratamento da base da estaca com o regulador de crescimento indutor de raízes, os carboidratos são translocados para a área tratada, aumentando a taxa de respiração e ocorrendo transformação dos carboidratos e compostos nitrogenados orgânicos. O regulador de crescimento pode acelerar o metabolismo normal e aumentar o número de primórdios radiculares.

\section{Experimento de outono}

$\mathrm{O}$ efeito da concentração de AIB sobre a variável altura foi significativo. Assim como no experimento de verão, a concentração de $2500 \mathrm{mg} / \mathrm{L}$ de AIB resultou em maior altura. A concentração zero de AIB resultou em menor altura (Figura 3).

A utilização de AIB nas concentrações avaliadas promoveu efeito significativo sobre a percentagem de estacas enraizadas (Figura 4a). A concentração de $2500 \mathrm{mg} / \mathrm{L}$ resultou em $95 \%$ de estacas enraizadas; já a menor quantidade $(61,67 \%)$ de estacas enraizadas foi no tratamento controle. Observou-se que o enraizamento no outono ( $95 \%$ ) não diferiu significativamente do verão (98\%). Apesar de não haver diferenças significativas entre as épocas, no período 


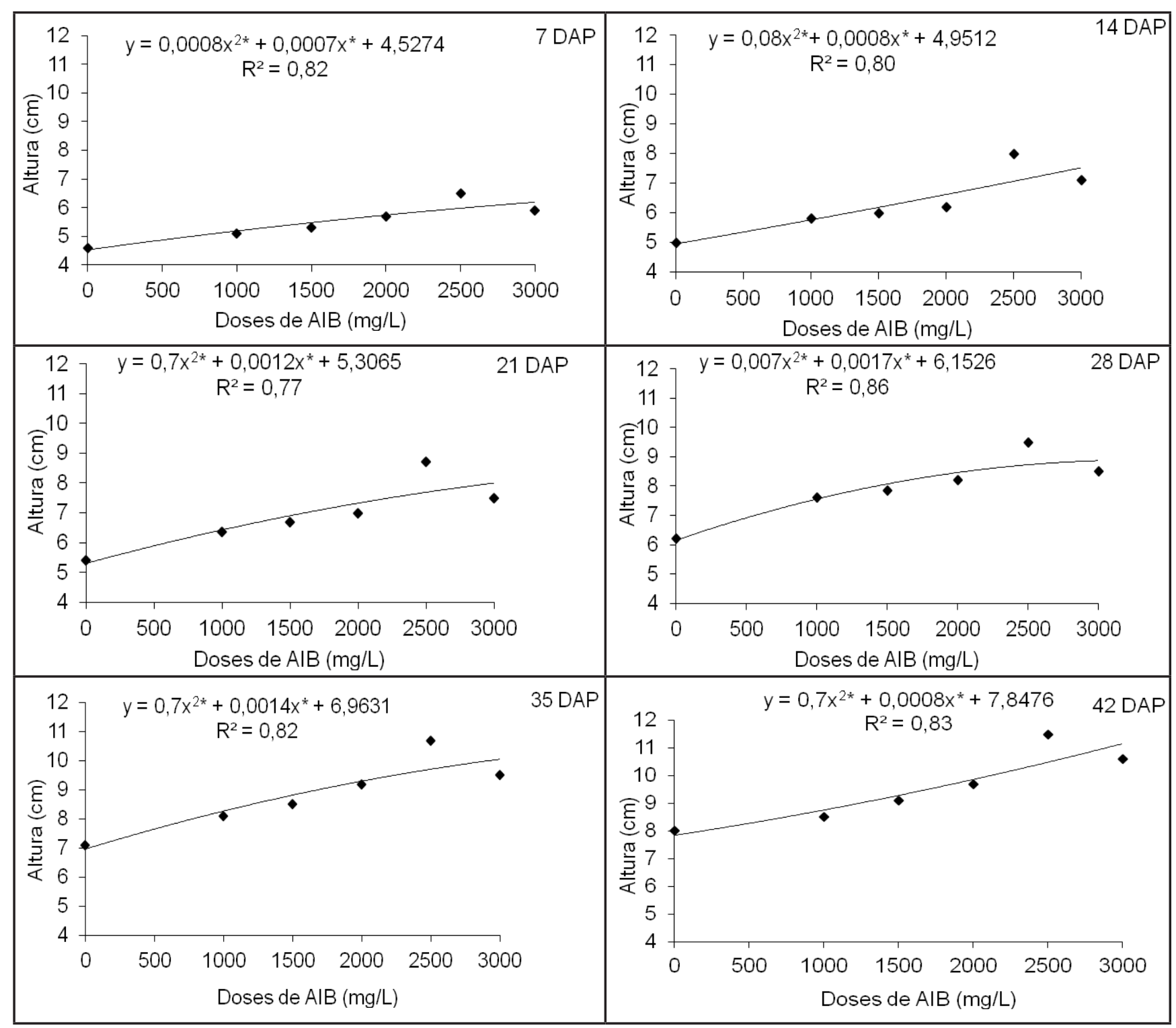

Figura 3. Alturas de estacas de alecrim (Rosmarinus officinalis) em função de diferentes doses de AIB, avaliadas aos 7, 14, 21, 28, 35 e 42 DAP (dias após o plantio), no outono.* significativo a $\mathrm{p}<0,01$ \{height of rosemary cuttings (Rosmarinus officinalis) in response to application of indole-butyric acid doses (IBA), evaluated at 7, 14, 21, 28, 35 and 42 DAP (days after planting) in autumn. * significant p<0.01\}. Dois Vizinhos, UTFPR, 2010.

de abril a junho, as temperaturas médias mensais de 19,$92 ; 16,95$ e $14,50^{\circ} \mathrm{C}$, respectivamente, foram inferiores às do experimento de verão.

Bona et al. (2010), avaliando as concentrações $(0,500,1000,2000$ e 3000 $\mathrm{mg} / \mathrm{L}$ de AIB), em lavanda (Lavandula dentata), constaram que a quantidade de estacas enraizadas aumentou com a concentração de AIB. A maior quantidade de estacas enraizadas (96\%), considerada alta pelos autores, foi obtida na concentração de $2000 \mathrm{mg} / \mathrm{L}$. Os autores também verificaram que a formação de raízes começou a diminuir com a dose de $3000 \mathrm{mg} / \mathrm{L}$, como indicativo de toxicidade do AIB.

A menor taxa de mortalidade de estacas (7\%) ocorreu na concentração de $2500 \mathrm{mg} / \mathrm{L}$ (Figura 4b). Verificou-se alta taxa de mortalidade $(38,33 \%)$ de estacas sem uso de AIB; supõe-se serem estacas que produzem quantidades insuficientes de auxinas endógenas, justificando a utilização de regulador de crescimento para enraizamento. A capacidade de uma estaca emitir raízes está em função de fatores endógenos e das condições ambientais proporcionadas ao enraizamento (Fachinello et al., 2005). De acordo com os autores, cada espécie possui seu valor máximo de aplicação exógena de regulador vegetal e este comportamento pode estar relacionado com o fato das estacas possuírem certa quantidade endógena de hormônios, promotores ou inibidores de enraizamento.

De acordo com Hartmann et al. (2011), a mortalidade de estacas varia conforme as condições intrínsecas destas e a influência das condições ambientais. Tracz et al. (2014) afirmam que a condição fisiológica da planta-matriz é determinante para o sucesso ou insucesso do enraizamento e está 


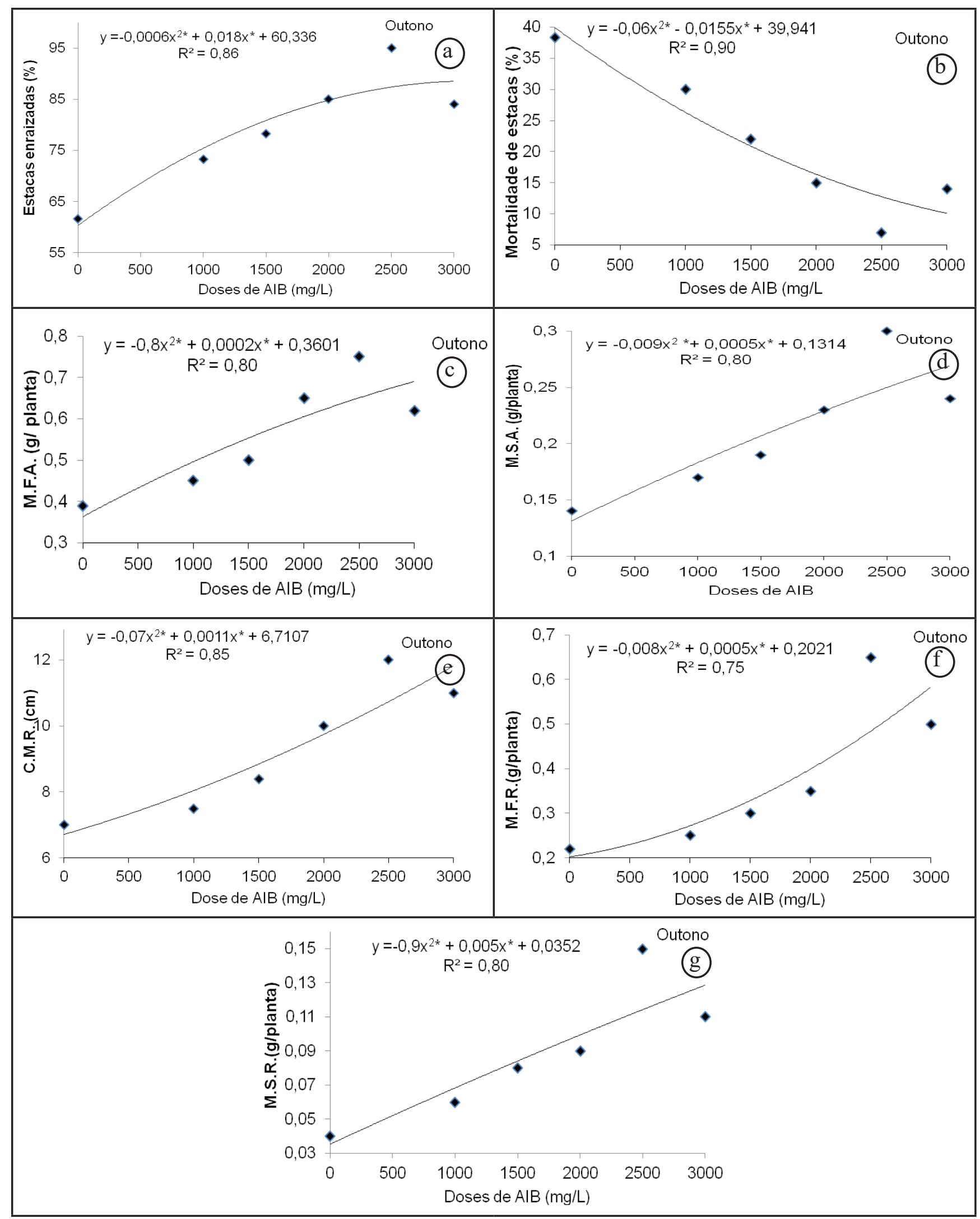

Figura 4. Estacas enraizadas (a); mortalidade de estacas (b); massa fresca da parte aérea (M.F.A.) (c); massa seca da parte aérea (M.S.A.) (d); comprimento de maior raiz (C.M.R.) (e); massa fresca das raízes (M.F.A.) (f) e massa seca das raízes (M.S.R) (g) de estacas de alecrim em resposta a diferentes concentrações de AIB, avaliadas aos 42 DAP (dias após o plantio) no outono.*significativo a p $<0,01$ \{rooted cuttings (a); mortality of cuttings (b); aboveground part fresh mass (M.F.A.) (c); aboveground part dry matter (M.S.A.) (d); length of the longest root (C.M.R.) (e); fresh matter of roots (M.F.A.) (f); dry matter of roots (M.S.R) (g) of rosemary stems in response to different concentrations of IBA), 42 DAP (days after planting) in autumn. *significant $\mathrm{p}<0.01\}$. Dois Vizinhos, UTFPR, 2010. 
relacionada ao conjunto de características internas da mesma, como conteúdo de água, características anatômicas, estação ou época do ano no momento da coleta das estacas. No presente estudo, a época do ano não influenciou no enraizamento de estacas. Trabalhos conduzidos por Scalon et al. (2003), testando o efeito dos tratamentos água, ácido indol acético (ANA), ANA+boro, AIB, AIB + boro e boro no enraizamento de estacas de alecrim, constataram que o comprimento da maior raiz $(11,5 \mathrm{~cm})$ foi obtido com AIB $(250 \mathrm{mg} / \mathrm{L})+$ boro (100 mg/L), no mês de agosto. O boro adicionado à auxina tem como função proporcionar aumento na formação e crescimento das raízes (Valmorbida \& Lessa, 2008).

Os resultados das massas fresca e seca da parte aérea apresentaram diferenças significativas em função das concentrações de AIB avaliadas (Figuras 4c; 4d). A concentração de $2500 \mathrm{mg} / \mathrm{L}$ de AIB resultou em maiores massas fresca e seca $(0,75$ e $0,30 \mathrm{~g} /$ planta $)$, respectivamente. Também, podem ter contribuído para os resultados de maior biomassa, o maior crescimento em altura e a maior área fotossintética das plantas nesse tratamento. Estacas enraizadas na concentração zero de AIB apresentaram os menores valores de massas fresca e seca.

Karimi et al. (2014) avaliaram o efeito das concentrações $(0 ; 100 ; 250$ e $500 \mathrm{mg} / \mathrm{L}$ ) de AIB no enraizamento e crescimento de mudas de tomilho (Thymus satureioides, Lamiaceae) e constataram que na concentração de $500 \mathrm{mg} / \mathrm{L}$ de AIB, as plantas que apresentaram a maior altura corresponderam em maior biomassa aérea. Os autores afirmam que o crescimento superior das raízes nesse tratamento contribuiu para o crescimento da parte aérea, justificado pelo aumento do número e altura das brotações.

Verificou-se que a aplicação de AIB nessa concentração não só aumentou o percentual de enraizamento, como também o comprimento da maior raiz, massas fresca e seca das raízes (Figuras $4 \mathrm{e} ; 4 \mathrm{f} ; 4 \mathrm{~g})$. Segundo Hartmann et al. (2011), a aplicação de auxina pode proporcionar maior velocidade de formação, qualidade e uniformidade do sistema radicial, neste caso evidenciado pelo aumento do comprimento da maior raiz. Para Zietemann \& Roberto (2007), a emissão de raízes em maior número e comprimento é fundamental quando o objetivo é a produção de mudas em escala comercial, visto que esses fatores são fundamentais no sucesso da implantação das áreas a campo. Além disso, o sistema radicular bem formado aumenta a área de solo a ser explorada, favorecendo a absorção de nutrientes e água, o que proporciona um melhor desenvolvimento da muda quando levada a campo (Carvalho Júnior et al., 2009).

Nicola et al. (2005) determinaram que o uso de AIB em plantas de sálvia (Sálvia officinalis) resultaram em efeito positivo no desenvolvimento do sistema radicular, tanto em termos de número de raízes e comprimento da raiz. Além disso, o uso de AIB foi reportado como necessário para garantir o enraizamento de estacas, possibilitando assim o plantio das mudas a campo na época certa e obtendo-se uma maior uniformidade das plantas.

Nas condições em que o estudo foi realizado, a época do ano não influenciou no enraizamento e no crescimento de mudas de alecrim. Os resultados indicam que a propagação vegetativa de alecrim por estacas apicais utilizando a concentração de $2500 \mathrm{mg} / \mathrm{L}$ de AIB favoreceu o enraizamento e crescimento em altura, comprimento de maior raiz, massas frescas e secas das raízes e da parte aérea de mudas de alecrim, nas épocas avaliadas. A utilização do ácido indolbultírico é uma maneira de tornar o enraizamento mais eficiente, possibilitando ao produtor de plantas medicinais benefícios em termos de maior qualidade de mudas de alecrim.

\section{REFERÊNCIAS}

BONA, CM; BIASI, LA; LIPSKI, B; MASETTO, MAM; DESCHAMPS, C. 2010. Enraizamento adventício de estacas de Lavandula dentata tratadas com auxina. Ciência Rural 40: 1210-1213.

BONA, CM; MASETTO, MAM; BIASI, LA; DESCHAMPS, C. 2012. Rooting induction of different Lavandula angustifolia accessions by auxin application. Semina 33: 175-182.

CARNEIRO, JGA. 1995. Produção e controle de qualidade de mudas florestais. Curitiba: UFPR. 451p.
CARVALHO JÚNIOR, WGO; MELO, MTP; MARTINS, ER. 2009. Comprimento da estaca no desenvolvimento de mudas de alecrimpimenta. Ciência Rural 39: 2199 -2202.

COELHO, MFB; MESSIAS, U. 2000. Efeito do ácido indolbutírico no enraizamento de estacas de alecrim. Horticultura Brasileira 18: 933-934.

CUNHA, AP; SILVA, AP; ROQUE, OR. 2003. Plantas medicinais e produtos vegetais em fitoterapia. Lisboa: Fundação Calouste Gulbenkian. 701p.

DEEN, SE; MAHMOUD, M. 1996. Comparative study between saponin and natural auxin on root growth of Rosemary (Rosmarinus officinalis) cutting. Acta Horticulturae 426: 635-642.

FACHINELLO, JC; HOFFMANN, A; NACHTIGAL, JC. 2005. Propagação de plantas frutiferas. Brasília: EMBRAPA. 221p.

FIGUEIREDO, LS; BONFIM, FPG; FERRAZ, EO; CASTRO, CE; SOUZA, MF; MARTINS, ER. 2009. Influência do ácido indolbutírico no enraizamento de alecrim-pimenta (Lippia sidoides) em leito com umidade controlada. Revista Brasileira de Plantas Medicinais 11: 33-36.

HARTMANN, HT; KESTER, DE; DAVIES, RT; GENEVE, RL. 2011. Plant propagation: principles and practices. $8^{\mathrm{a}}$ ed. New Jersey: Prentice Hall. 915p.

KARIMI, M; BERRICHI, A; BOUKROUTE, A. 2014. Study of vegetative propagation by cuttings of Thymus satureioides. Journal of Materials Environmental Science 5: 13201325.

KRAMER, PJ; KOZLOWSKI, T. 1972. Fisiologia das árvores. Lisboa: Fundação Calouste Gulbenkian, 745p.

LORENZI, H; MATOS, FJA. 2008. Plantas medicinais no Brasil: nativas e exóticas. 2 ed. Nova Odessa: Instituto Plantarum. 544p.

MARTINS, ER.1998. Plantas medicinais. Viçosa: UFV. 220p.

MIRANDA, CS; CHALFUN, NJ; HOFFMANN, A; DUTRA, LF; COELHO, GVA. 2004. Enxertia recíproca e AIB como fatores indutores do enraizamento de estacas lenhosas dos porta-enxertos de pessegueiro 'Okinawa' e umezeiro. Ciência e Agrotecnologia 28: 778-784.

NICOLA, S; FONTANA, E; HOEBERECHTS, J; SAGLIETTI, D. 2005. Rooting products and cutting timing on sage (Salvia officinalis L.) propagation. Acta Horticulturae 676: 135-141.

OLIVEIRA, LM; NEPOMUCENO, CF; FREITAS, NP; PEREIRA, DMS; SILVA, GC; LUCCHESE, AM. 2011. Propagação vegetativa de Hyptis leucocephala Mart. ex Benth. e Hyptis platanifolia Mart. ex Benth. (Lamiaceae). Revista Brasileira de Plantas Medicinais 13: 73-78.

PARADIKOVIC, N; ZELJKOVIĆ, S; TKALEC, M.; VINKOVIĆ, T; DERVIĆ, I.; MARIĆ, M. 2013. Influence of rooting powder on propagation of sage (Salvia officinalis L.) and rosemary (Rosmarinus officinalis 1.) with green cuttings. Poljoprivreda 19: 10-15.

PASQUAL, M; CHALFUN, NNJ; RAMOS, JD; VALE, MR; SILVA, CRR. 2001. Fruticultura 
comercial: propagação de plantas frutíferas. Lavras: UFLA. 137p.

PIMENTA, MR; FERNANDES, LS; PEREIRA, UJ; GARCIA, LS; LEAL, SR; LEITÃO, SG; SALIMENA, FR; VICCINI, LF; PEIXOTO, PHP. 2007. Floração, germinação e estaquia em espécies de Lippia L. (Verbenaceae). Revista Brasileira de Botânica 30: 211-220.

RAMOS, JD; MATOS, LES; GONTIJO, TCA; PIO, R; JUNQUEIRA, KP; SANTOS, FC. 2003. Enraizamento de estacas herbáceas de 'mirabolano' (Prunus cerasifera EHRN) em diferentes substratos e concentrações de ácido indolbutírico. Revista Brasileira de Fruticultura 25: 189-91.

SAS INSTITUTE .2014. SAS Studio. Disponível em: http://www.sas.com/en_us/software/ university-edition.html//. Acessado em 15 de agosto de 2014.

SARTORATTO, A; DUARTE, MCT; DELARMELINA, C; REHDER, VLG; FIGUEIRA, GM; MACHADO, ALM. 2004. Composition and antimicrobial activity of essential oils from aromatic plants used in Brazil. Brazilian Journal of Microbiology 35: 275-280.

SCALON, SPQ; RAMOS, MBM; VIEIRA, MC. 2003. Auxinas e boro no comprimento da maior raiz e número de estacas enraizadas de guaco (Mikania glomerata Sprengel), alecrim (Rosmarinus officinalis L.) e carqueja (Baccharis trimera Less A.P.D.C.) em duas épocas de plantio. Revista Brasileira de Plantas Medicinais 5: 71-76.
TRACZ, V; CRUZ-SILVA, CTA; LUZ, MZ. 2014. Produção de mudas de penicilina (Alternanthera brasiliana (L.) Kuntze) via estaquia. Revista Brasileira de Plantas Medicinais 16: 644-648.

VALMORBIDA, J; LESSA, AO. 2008. Enraizamento de estacas de Ginkgo biloba tratadas com ácido indolbutírico e ácido bórico. Ciência e Agrotecnologia 32: 398-401.

VON HERTWIG, IF. 1991. Plantas aromáticas e medicinais. São Paulo: Icone. 450p.

ZIETEMANN, C; ROBERTO, SR. 2007. Efeito de diferentes substratos e épocas de coleta no enraizamento de estacas herbáceas de goiabeira, cvs. Paluma e Século XXI. Revista Brasileira de Fruticultura 29: 31-36. 